\title{
Intraoperative mechanical ventilation practice in thoracic surgery patients and its association with postoperative pulmonary complications: results of a multicenter prospective observational study
}

Christopher Uhlig ${ }^{1 \dagger}$, Ary Serpa Neto ${ }^{2 \dagger}$, Meta van der Woude ${ }^{3 \dagger}$, Thomas Kiss $^{1}$, Jakob Wittenstein ${ }^{1}$, Benjamin Shelley ${ }^{4}$, Helen Scholes ${ }^{4}$, Michael Hiesmayr ${ }^{5}$, Marcos Francisco Vidal Melo ${ }^{6}$, Daniele Sances ${ }^{7}$, Nesil Coskunfirat ${ }^{8}$, Paolo Pelosi ${ }^{9}$, Marcus Schultz ${ }^{3}$, Marcelo Gama de Abreu ${ }^{1 *}$ (iD and LAS VEGAS\# investigators, Protective Ventilation Network (PROVEnet), Clinical Trial Network of the European Society of Anaesthesiology

\begin{abstract}
Background: Intraoperative mechanical ventilation may influence postoperative pulmonary complications (PPCs). Current practice during thoracic surgery is not well described.

Methods: This is a post-hoc analysis of the prospective multicenter cross-sectional LAS VEGAS study focusing on patients who underwent thoracic surgery. Consecutive adult patients receiving invasive ventilation during general anesthesia were included in a one-week period in 2013. Baseline characteristics, intraoperative and postoperative data were registered. PPCs were collected as composite endpoint until the 5th postoperative day. Patients were stratified into groups based on the use of one lung ventilation (OLV) or two lung ventilation (TLV), endoscopic vs. non-endoscopic approach and ARISCAT score risk for PPCs. Differences between subgroups were compared using $x^{2}$ or Fisher exact tests or Student's $t$-test. Kaplan-Meier estimates of the cumulative probability of development of PPC and hospital discharge were performed. Cox-proportional hazard models without adjustment for covariates were used to assess the effect of the subgroups on outcome.

(Continued on next page)
\end{abstract}

\footnotetext{
* Correspondence: mgabreu@uniklinikum-dresden.de

${ }^{\dagger}$ Christopher Uhlig, Ary Serpa Neto and Meta van der Woude contributed equally to this work.

'Department of Anaesthesiology and Intensive Care Medicine, Pulmonary Engineering Group, University Hospital Carl Gustav Carus at the Technische Universität Dresden, Fetscherstr. 74, 01307 Dresden, Germany

Full list of author information is available at the end of the article
}

C C The Author(s). 2020 Open Access This article is licensed under a Creative Commons Attribution 4.0 International License, which permits use, sharing, adaptation, distribution and reproduction in any medium or format, as long as you give appropriate credit to the original author(s) and the source, provide a link to the Creative Commons licence, and indicate if changes were made. The images or other third party material in this article are included in the article's Creative Commons licence, unless indicated otherwise in a credit line to the material. If material is not included in the article's Creative Commons licence and your intended use is not permitted by statutory regulation or exceeds the permitted use, you will need to obtain permission directly from the copyright holder. To view a copy of this licence, visit http://creativecommons.org/licenses/by/4.0/ The Creative Commons Public Domain Dedication waiver (http://creativecommons.org/publicdomain/zero/1.0/) applies to the data made available in this article, unless otherwise stated in a credit line to the data. 
(Continued from previous page)

Results: From 10,520 patients enrolled in the LAS VEGAS study, 302 patients underwent thoracic procedures and were analyzed. There were no differences in patient characteristics between OLV Vs. TLV, or endoscopic vs. open surgery. Patients received $V_{T}$ of $7.4 \pm 1.6 \mathrm{~mL} / \mathrm{kg}$, a PEEP of $3.5 \pm 2.4 \mathrm{cmH}_{2} \mathrm{O}$, and driving pressure of $14.4 \pm 4.6$ $\mathrm{cmH}_{2} \mathrm{O}$. Compared with TLV, patients receiving OLV had lower $V_{\mathrm{T}}$ and higher peak, plateau and driving pressures, higher PEEP and respiratory rate, and received more recruitment maneuvers. There was no difference in the incidence of PPCs in OLV vs. TLV or in endoscopic vs. open procedures. Patients at high risk had a higher incidence of PPCs compared with patients at low risk (48.1\% vs. 28.9\%; hazard ratio, $1.95 ; 95 \% \mathrm{Cl} 1.05-3.61 ; p=0.033)$. There was no difference in the incidence of severe PPCs. The in-hospital length of stay (LOS) was longer in patients who developed PPCs. Patients undergoing OLV, endoscopic procedures and at low risk for PPC had shorter LOS.

Conclusion: PPCs occurred frequently and prolonged hospital LOS following thoracic surgery. Proportionally large tidal volumes and high driving pressure were commonly used in this sub-population. However, large RCTs are needed to confirm these findings.

Trial registration: This trial was prospectively registered at the Clinical Trial Register (www.clinicaltrials.gov; NCT016 01223; registered May 17, 2012.)

Keywords: Thoracic surgery, Mechanical ventilation, General anesthesia, Perioperative complications

\section{Background}

Approximately 234 million major surgical procedures are undertaken worldwide every year [1]. Among these, approximately 7 million patients develop major complications resulting in one million deaths during surgery or in-hospital stay, contributing to an estimated mortality rate after anesthesia of 34 per million [1, 2]. According to the 'Local assessment of ventilatory management during general anesthesia for surgery and effects on postoperative pulmonary complications' (LAS VEGAS) trial, postoperative pulmonary complications (PPC) occur in a significant proportion of surgical patients [3]. However, since thoracic surgery requires a differentiated ventilatory approach, those patients were excluded from the primary analysis of the LAS VEGAS study. In thoracic surgery, conventional methods to prevent and treat hypoxemia during one lung ventilation (OLV) can be harmful to the lung tissue: high fraction of inspired oxygen (FIO2) and low (or no) positive end-expiratory pressure (PEEP) both can promote atelectasis, whereas high tidal volume (VT) can cause baro- and volutrauma [4]. The type of thoracic surgery (open or endoscopic) as well as the intraoperative mechanical ventilation settings may also influence PPCs.

Intraoperative mechanical ventilation with low $\mathrm{V}_{\mathrm{T}}$, low driving pressure, and low to moderate PEEP improved postoperative lung function and even outcome in patients undergoing open abdominal surgery $[5,6]$. When low $\mathrm{V}_{\mathrm{T}}$ was used in abdominal surgery, high PEEP combined with recruitment maneuvers, as compared to low PEEP without recruitment maneuvers, did not add to the protection against PPCs [7].

The present study aimed to characterize the current mechanical ventilation practice during general anesthesia for thoracic surgery, describe the incidence of PPCs, and investigate possible associations between type of surgery (open vs. endoscopic), type of ventilation (OLV or two lung ventilation) and risk for PPCs (low risk vs high) with the incidence of PPCs. We hypothesized that intraoperative mechanical ventilation, as recommended in the literature, namely with low $\mathrm{V}_{\mathrm{T}}$, low driving pressure, and low to moderate PEEP [8], is not commonly used during thoracic surgery, and that the incidence of PPCs is higher in this surgical population than in non-thoracic surgery.

\section{Methods}

\section{Study design and sites}

The present work is a post hoc analysis of the 'Local assessment of ventilatory management during general anesthesia for surgery and effects on postoperative pulmonary complications' (LAS VEGAS trial) [3]. The LAS VEGAS trial protocol was first approved by the institutional review board of the Academic Medical Center, Amsterdam, The Netherlands (W12_190\#12.17.0227) and registered at clinicaltrials.gov (NCT01601223). The protocol of this trial was published elsewhere [9].

\section{Study population and data collection}

Consecutive adult patients receiving invasive ventilation during general anesthesia for elective or non-elective surgery were eligible for participation in the study, which ran for seven predefined days in each country, selected by the national coordinator, in the period between January 14th and March 4th, 2013. Patients were excluded from participation if they were aged $<18$ years, or scheduled for pregnancy related surgery, surgical procedures outside the operating room, or procedures involving cardio-pulmonary bypass. 
The patient database of the LAS VEGAS trial was searched for eligible patients who received either open thoracic surgery, thoracoscopic or thoracoscopy assisted surgery (both summarized as endoscopic surgery), with or without OLV. These data have not been considered in previous analyses.

Reasonable parameters of baseline characteristics, intraoperative data and preoperative risk factors for PPCs were identified from previous studies [10-13]. During the intraoperative period, data describing ventilation settings and vital parameters, as well as episodes of hypoxia $\left(\mathrm{SpO}_{2}<92 \%\right)$, use of recruitment maneuvers, airway pressure reduction, presence of expiratory flow limitation, hypotension (mean arterial pressure $<60 \mathrm{mmHg}$ ), use of vasoactive drugs, and new arrhythmias, was collected. Postoperative residual curarisation with neuromuscular blocking agents (NMBAs), defined as trainof-four stimulation (TOF) ratio $<0.9$, was documented.

The definition of protective mechanical ventilation is still under debate. For this analysis it was based on recent recommendations $[8,14-16]$. Patients were considered to be have been protectively ventilated "as recommended" if PEEP $\geq 5 \mathrm{cmH}_{2} \mathrm{O}$ and $\mathrm{V}_{\mathrm{T}} \leq 8 \mathrm{ml} / \mathrm{kg}$ PBW during TLV $[8,14,17]$, and PEEP $\geq 5 \mathrm{cmH}_{2} \mathrm{O}$ and $\mathrm{V}_{\mathrm{T}} \leq 5 \mathrm{ml} / \mathrm{kg}$ PBW during OLV [18-20].

The occurrence of PPCs is presented as a collapsed composite of PPCs in the first five postoperative days. The following PPCs were scored daily from the day of surgery until hospital discharge or postoperative day 5 : 1) need for supplementary oxygen (due to $\mathrm{PaO}_{2}<60$ $\mathrm{mmHg}$ or $\mathrm{SpO}_{2}<90 \%$ in room air, excluding oxygen supplementation given as standard care or as continuation of preoperative therapy), 2) respiratory failure $\left(\mathrm{PaO}_{2}<60 \mathrm{mmHg}\right.$ or $\mathrm{SpO}_{2}<90 \%$ despite oxygen therapy, or need for non-invasive mechanical ventilation), 3 ) unplanned new or prolonged invasive or non-invasive mechanical ventilation, 4) acute respiratory distress syndrome, 5) pneumonia. Severe PPCs were defined as the occurrence of one or more of the complications 2-5. Patient data were anonymized before entry onto a password secured, web-based electronic case record form (OpenClinica, Boston, MA, USA).

\section{Statistical analysis}

Patients were stratified into groups based on: 1) use or not of OLV (OLV vs. only TLV); 2) use or not of an endoscopic approach (endoscopic vs. open); and 3) risk for PPC according to ARISCAT (low risk [ARISCAT < 26 ] vs. moderate-to-high risk [ARISCAT $\geq 26$ ] Supplemental Table 2, Additional file 1). The ventilatory data, which were collected hourly, were first averaged for each patient according to the number of observations (median of the value). In a longitudinal analysis, this data is presented for the first, second, third, fourth and last hour of surgery. All data are presented for the whole population and for the subgroups. In-hospital length of stay (LOS) and in-hospital mortality was censored at postoperative day 28. Proportions are compared using $X^{2}$ or Fisher exact tests and continuous variables are compared using the Mann-Whitney $U$ Test, as appropriate.

The distributions of combinations of tidal volume size and PEEP level are presented in scatter plots. Cut-offs of $6 \mathrm{ml} / \mathrm{kg}$ PBW for tidal volume, and $5 \mathrm{cmH}_{2} \mathrm{O}$ for PEEP were chosen to form the matrices. These cut-offs were based on widely accepted values of each variable, or according to normal daily practice. The driving pressure was defined as plateau pressure (Pplat) minus the PEEP level.

Kaplan-Meier estimates of the cumulative probability of development of PPC and hospital discharge were performed. Cox proportional hazard models without adjustment for covariates were used to assess the effect of the subgroups on outcome. The proportionality assumption was tested with scaled Schoenfeld residuals. Adjustments for multiple comparisons were not performed and no assumption for missing data was done. Statistical significance was considered to be at two-sided $p<0.05$. All analyses were performed with $\mathrm{R}$ version 3.4 .1 (http:// www.R-project.org/).

\section{Results}

From 10,520 patients enrolled in the LAS VEGAS study, 302 patients underwent thoracic procedures (Supplemental Figure 1, Additional file 1). Characteristics of patient and surgery are shown in Table 1 . In this subpopulation of 302 thoracic surgical patients, 55\% (168/ 302) received OLV, $15.2 \%$ (46/302) were operated with an endoscopic approach and $87.4 \%(264 / 302)$ had moderate-to-high risk for PPCs.

Characteristics of patients undergoing procedures with OLV vs. TLV, and endoscopic vs. open were comparable. Patients with moderate-to-high risk for PPCs were different from those at low risk with respect to age, gender, BMI, ASA status, COPD prevalence and planned duration of surgery (Table 1).

\section{Intra-operative characteristics}

Patients operated under OLV received more often double-lumen tubes and had more frequently lung or pleural surgery than those operated under TLV (Table 1). Use of epidural anesthesia was less and duration of surgery shorter in endoscopic compared to non-endoscopic surgery (Table 1).

Patients at moderate-to-high risk for PPC received more frequently antibiotic prophylaxis and epidural anesthesia, and had longer duration of surgery as well as anesthesia, compared with patients at low risk (Table 1). 


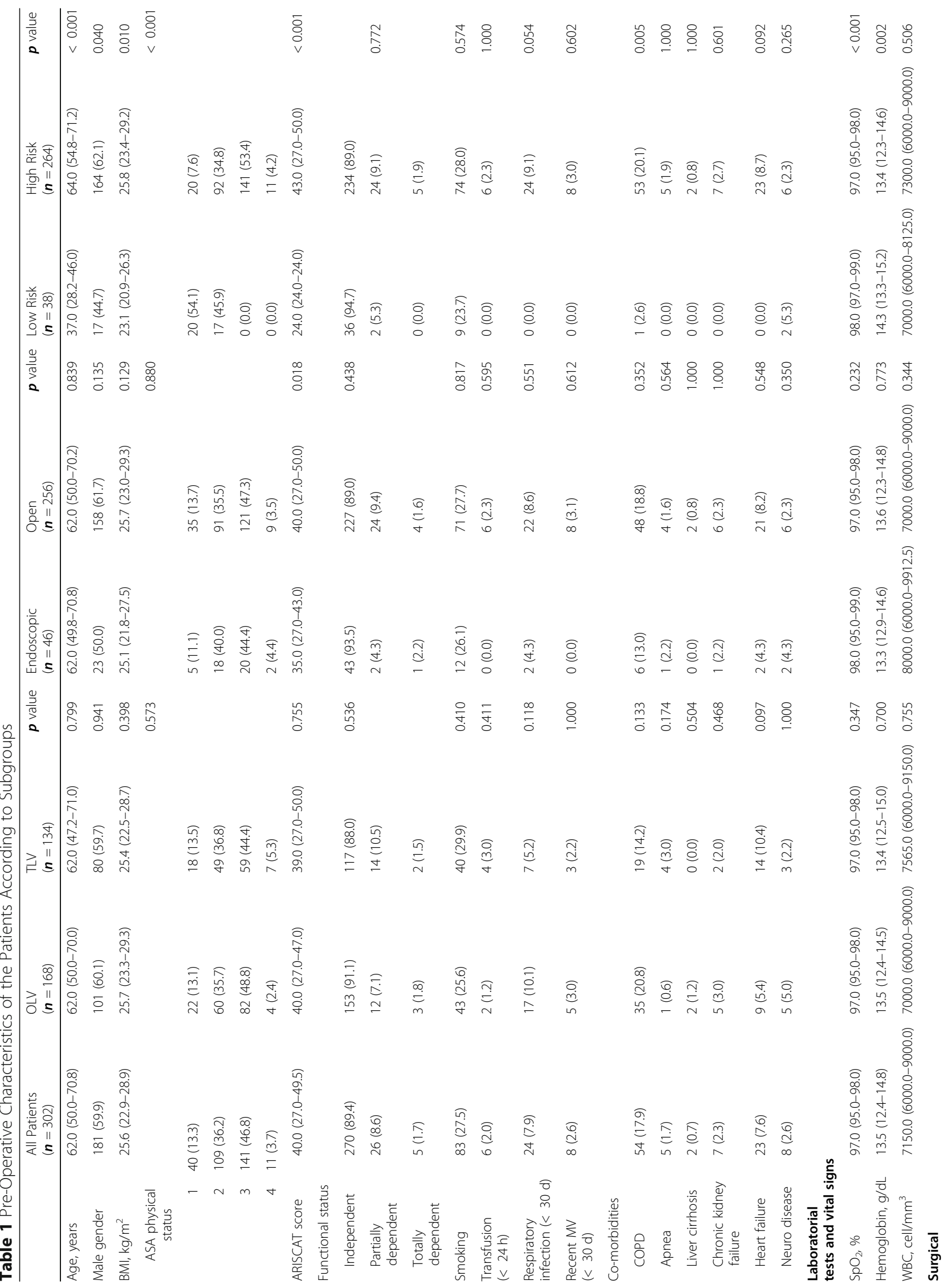




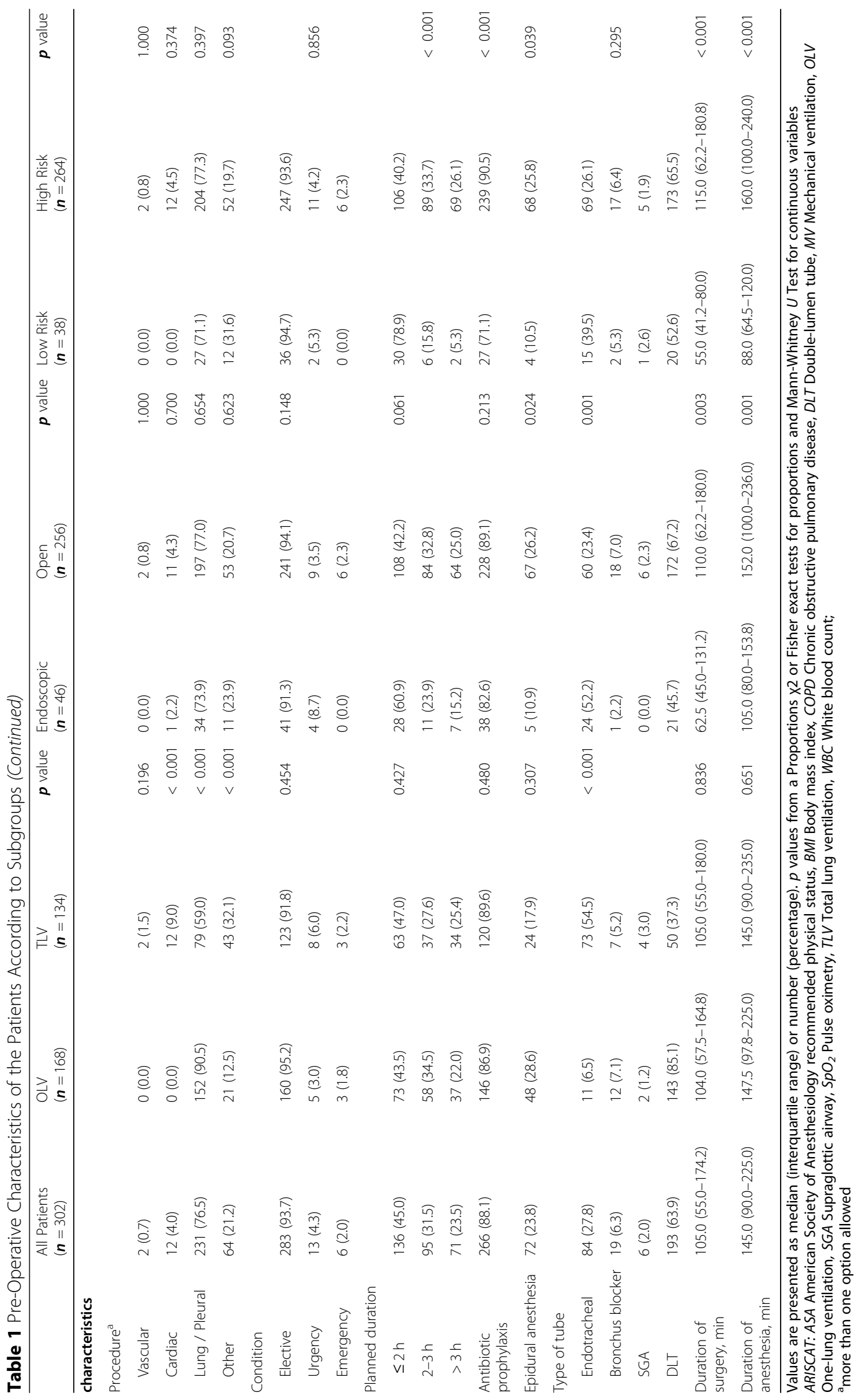


The amounts of crystalloids, colloids, albumin and packed red blood cells was higher in open vs. endoscopic surgery, and in patients at moderate-to-high vs. low risk for PPC (Table 2).

\section{Mechanical ventilation}

Patients were ventilated with $\mathrm{V}_{\mathrm{T}}$ of $7.4 \pm 1.6 \mathrm{ml} / \mathrm{kg} \mathrm{PBW}$, PEEP of $3.5 \pm 2.4 \mathrm{cmH}_{2} \mathrm{O}$, and driving pressure of $14.4 \pm$ $4.6 \mathrm{cmH}_{2} \mathrm{O}$ (Table 2). Compared to patients operated solely under TLV, patients receiving OLV had lower $\mathrm{V}_{\mathrm{T}}$, higher peak, plateau and driving pressures, as well as PEEP and respiratory rate, and received higher number of recruitment maneuvers (Table 2). Protective ventilation was used in $14.8 \%$ (41/302) of all patients, mainly during TLV. The ventilatory management of patients undergoing endoscopic and non-endoscopic procedures did not differ significantly. Patients at moderate-to-high risk for PPC had higher levels of PEEP, and received more recruitment maneuvers than patients at low risk (Table 2).

Values of ventilator settings along time are shown in Supplemental Figures 2 through 4 (Additional file 1). Patients operated under OLV had higher $\mathrm{FiO}_{2}$ compared with patients operated under TLV (Supplemental Figure 2, Additional file 1). The combinations of $V_{T}$ and PEEP according to subgroups are shown in Supplemental Figures 5 through 7 (Additional file 1).

\section{Primary outcome}

The overall incidence of PPCs in this population was 45.7\% (138/302), and did not differ significantly between OLV vs. TLV (82/168 vs. $56 / 134,48.8 \%$ vs. $41.8 \%, p=0.223$, total number and percentage respectively), and endoscopic vs. open procedures (16/ 46 vs. $122 / 256,34.8 \%$ vs. $47.7 \%, p=0.106$, total number and percentage respectively, Table 3, Fig. 1). Patients at moderate-to-high risk showed an increased incidence of PPC compared to patients at lower risk (48.1\% vs. $28.9 \%$; hazard ratio, 1.95 ; $95 \%$ CI $1.05-$ 3.61; $p=0.033)$, mainly due to unplanned need for supplemental oxygen (Table 3, Fig. 1).

\section{Secondary outcomes}

The incidence of severe PPCs, unplanned ICU admission and hospital mortality did not differ among groups (Table 3). The incidence of hypotension was decreased in endoscopic compared to open procedures, and in patients at lower compared to moderate-to-high risk of PPCs (Table 3).

The LOS was increased in patients who developed PPCs (Supplemental Figure 8, Additional file 1), and shorter in patients operated under OLV vs. TLV, endoscopic vs. open, and those with low vs. moderate-to-high risk for PPC (Table 3, Fig. 2).

\section{Discussion}

In this population of patients undergoing thoracic surgery: 1) mechanical ventilation differed from those recommended for lung protection in $85.2 \%$ of all patients; 2) patients under OLV received lower $V_{T}$, higher peak, plateau and driving pressures, higher PEEP levels and respiratory rate, and received more recruitment maneuvers compared with TLV; 3) the overall incidence of PPCs was as high as $45.7 \%$; 4) PPCs were more common among patients with higher ARISCAT score or comorbidities, but not increased following open vs. endoscopic procedures, or OLV vs. TLV; 6) PPCs were associated with increased LOS.

To our knowledge, this is the first prospective observational investigation addressing the practice of mechanical ventilation and incidence of PPCs in thoracic anesthesia. The main strengths of our study are that data was stored, analyzed and reported according to international standards [21].

High $V_{T}$ strategies, usually accompanied by low or zero PEEP, have been used to prevent intraoperative atelectasis [22, 23]. However, this may cause overdistension (volutrauma), and repetitive collapse-reopening of lung units (atelectrauma), which can injure the lungs and lead to PPCs [24]. A protective ventilation approach consisting mainly of low $\mathrm{V}_{\mathrm{T}}$ reduces the incidence of PPCs [7, 25]. This seems to apply also to thoracic anesthesia but this claim is not undisputed [26-28]. The present study shows that protective mechanical ventilation, as recommended, was used in less than $15 \%$ of patients undergoing thoracic surgery. Different possible reasons might explain this finding: 1) the concept of protective ventilation during surgery is still not widespread among anesthesiologists; 2) the role of single components of mechanical ventilation in lung protection, especially of PEEP, is still poorly defined, leading anesthesiologists to set values according to their own preferences; 3) sound evidence from large RCTs demonstrating the benefit of protective mechanical ventilation in thoracic surgical patients is still missing; 4) thoracic surgical procedures usually last less than 1 hour, which might be deemed as too short to benefit from protective mechanical ventilation; 5) mechanical ventilation settings guided by driving pressure may result in $V_{T}$ and PEEP outside the range that has been recommended for protective mechanical ventilation.

The incidence of PPCs after surgery is influenced by patient-related factors, and type of surgery. In a mixed surgical population without surgery involving cardiopulmonary bypass, $10.4 \%$ of patients developed PPCs within the first postoperative 5 days; values ranged from $6.7 \%$ in plastic/cutaneous procedures to $38.2 \%$ in transplant surgery [3]. In open abdominal surgery, PPCs were reported in 10.5 to $39.0 \%$ of patients, despite the use of a 


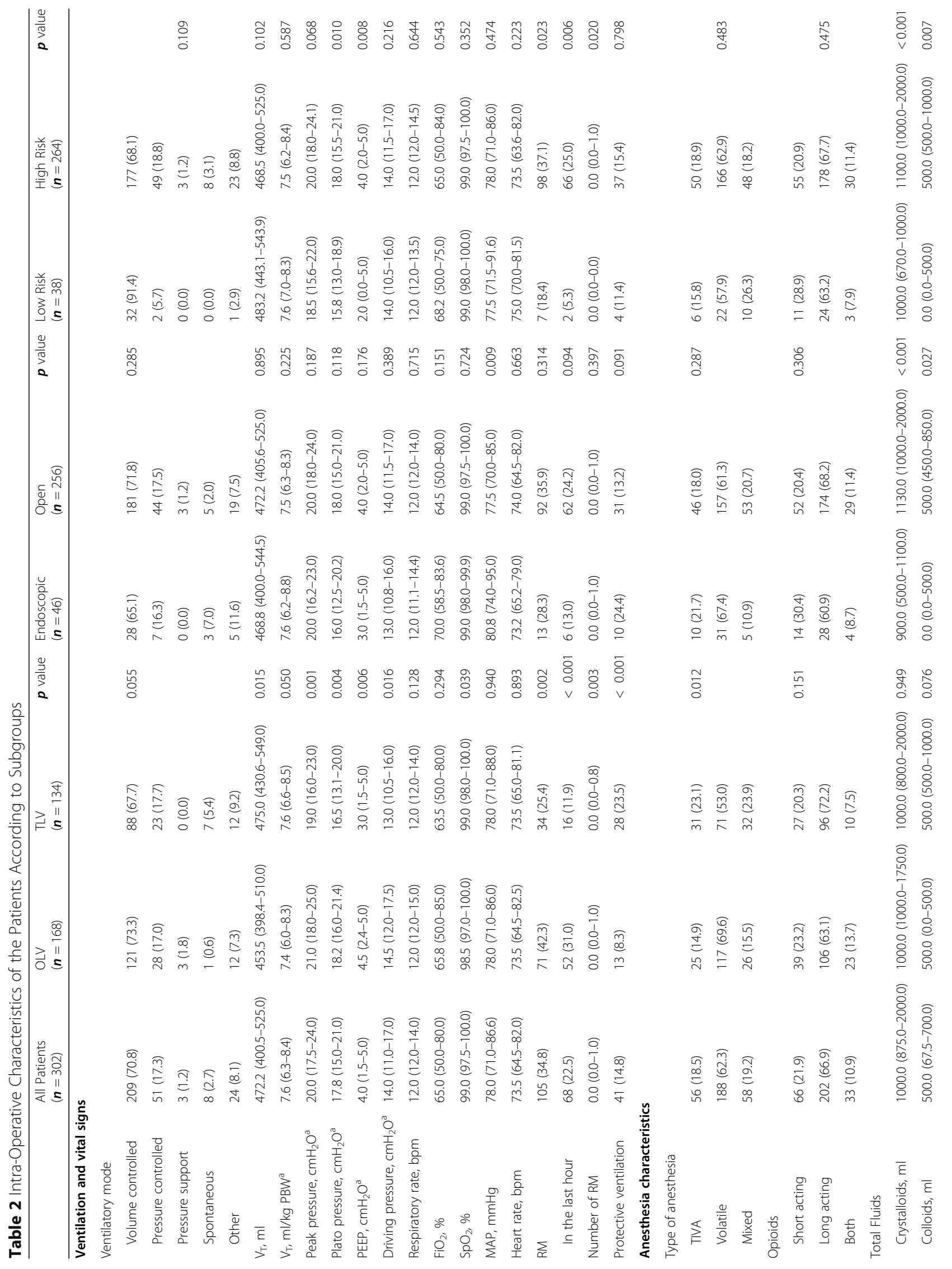




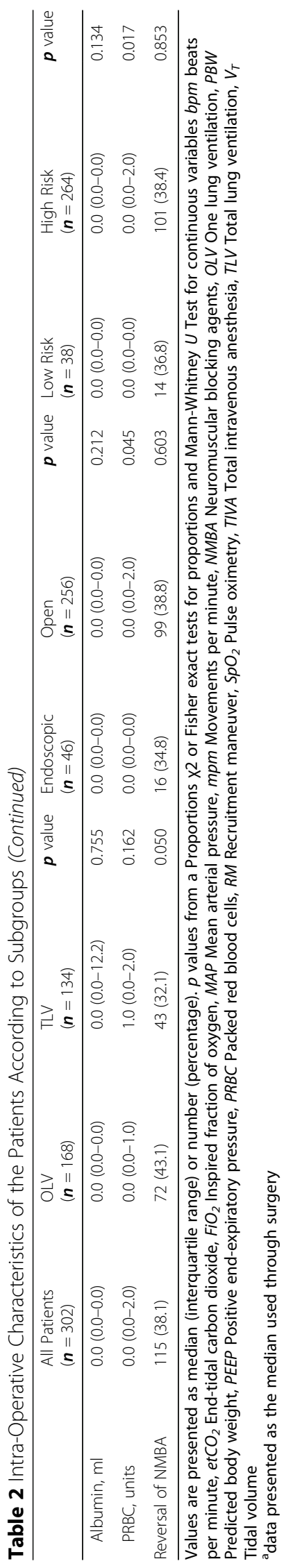


Table 3 Clinical Outcomes of the Patients According to Subgroups

\begin{tabular}{|c|c|c|c|c|c|c|c|c|c|c|}
\hline & $\begin{array}{l}\text { All Patients } \\
(\boldsymbol{n}=302)\end{array}$ & $\begin{array}{l}\text { OLV } \\
(\boldsymbol{n}=168)\end{array}$ & $\begin{array}{l}\text { TLV } \\
(\boldsymbol{n}=134)\end{array}$ & $\boldsymbol{p}$ value & $\begin{array}{l}\text { Endoscopic } \\
(\boldsymbol{n}=46)\end{array}$ & $\begin{array}{l}\text { Open } \\
(\boldsymbol{n}=256)\end{array}$ & $\boldsymbol{p}$ value & $\begin{array}{l}\text { Low Risk } \\
(\boldsymbol{n}=38)\end{array}$ & $\begin{array}{l}\text { High Risk } \\
(\boldsymbol{n}=264)\end{array}$ & $\boldsymbol{p}$ value \\
\hline \multicolumn{11}{|l|}{ Primary outcome } \\
\hline PPC & $138(45.7)$ & $82(48.8)$ & $56(41.8)$ & 0.223 & $16(34.8)$ & $122(47.7)$ & 0.106 & $11(28.9)$ & $127(48.1)$ & 0.026 \\
\hline Need of oxygen & $109(36.1)$ & $65(38.9)$ & $44(32.8)$ & 0.274 & $12(26.1)$ & $97(38.0)$ & 0.120 & $8(21.1)$ & $101(38.4)$ & 0.037 \\
\hline Respiratory failure & $26(8.6)$ & $15(8.9)$ & $11(8.2)$ & 0.824 & $1(2.2)$ & $25(9.8)$ & 0.148 & $2(5.3)$ & $24(9.1)$ & 0.755 \\
\hline Invasive MV & $26(8.6)$ & $14(8.3)$ & $12(9.0)$ & 0.848 & $3(6.5)$ & $23(9.0)$ & 0.778 & $1(2.6)$ & $25(9.5)$ & 0.222 \\
\hline NIV & $15(5.0)$ & $10(6.0)$ & $5(3.7)$ & 0.377 & $2(4.3)$ & $13(5.1)$ & 1.000 & $1(2.6)$ & $14(5.3)$ & 0.702 \\
\hline ARDS & $4(1.3)$ & $4(2.4)$ & $0(0.0)$ & 0.132 & $0(0.0)$ & $4(1.6)$ & 1.000 & $0(0.0)$ & $4(1.5)$ & 1.000 \\
\hline Pneumonia & $8(2.6)$ & $6(3.6)$ & $2(1.5)$ & 0.307 & $2(4.3)$ & $6(2.3)$ & 0.350 & $1(2.6)$ & $7(2.7)$ & 1.000 \\
\hline \multicolumn{11}{|l|}{ Secondary outcomes } \\
\hline Severe $\mathrm{PPC}^{\mathrm{a}}$ & $53(17.5)$ & $30(17.9)$ & $23(17.2)$ & 0.875 & $7(15.2)$ & $46(18.0)$ & 0.651 & $4(10.5)$ & 49 (18.6) & 0.223 \\
\hline \multicolumn{11}{|l|}{ Intra-OP complications } \\
\hline Desaturation & $61(20.2)$ & $38(22.6)$ & $23(17.2)$ & 0.240 & $7(15.2)$ & $54(21.1)$ & 0.360 & $5(13.2)$ & $56(21.2)$ & 0.247 \\
\hline Unplanned RM & $48(15.9)$ & $31(18.5)$ & $17(12.7)$ & 0.173 & $7(15.2)$ & $41(16.0)$ & 0.891 & $3(7.9)$ & $45(17.0)$ & 0.149 \\
\hline Pressure reduction & $36(11.9)$ & $27(16.1)$ & $9(6.7)$ & 0.012 & $5(10.9)$ & $31(12.1)$ & 0.811 & $2(5.3)$ & $34(12.9)$ & 0.281 \\
\hline Flow limitation & $3(1.0)$ & $2(1.2)$ & $1(0.8)$ & 1.000 & $0(0.0)$ & $3(1.2)$ & 1.000 & $0(0.0)$ & $3(1.1)$ & 1.000 \\
\hline Hypotension & $102(33.8)$ & $60(35.7)$ & $42(31.3)$ & 0.424 & $8(17.4)$ & $94(36.7)$ & 0.010 & $3(7.9)$ & $99(37.5)$ & $<0.001$ \\
\hline Vasopressors & $113(37.4)$ & $65(38.7)$ & $48(35.8)$ & 0.608 & $13(28.3)$ & $100(39.1)$ & 0.163 & $3(7.9)$ & $110(41.7)$ & $<0.001$ \\
\hline New arrhythmias & $6(2.0)$ & $3(1.8)$ & $3(2.2)$ & 1.000 & $0(0.0)$ & $6(2.3)$ & 0.595 & $0(0.0)$ & $6(2.3)$ & 1.000 \\
\hline ICU admission ${ }^{b}$ & $6(2.0)$ & $2(1.2)$ & $4(3.0)$ & 0.411 & $0(0.0)$ & $6(2.3)$ & 0.595 & $0(0.0)$ & $6(2.3)$ & 1.000 \\
\hline Hospital LOS, days & $6.0(3.0-10.0)$ & $6.0(4.0-11.0)$ & $5.0(3.0-9.0)$ & $0.010^{c}$ & $3.0(1.0-7.5)$ & $6.0(4.0-10.0)$ & $<0.001^{c}$ & $4.0(1.0-6.0)$ & $6.0(4.0-10.0)$ & $<0.001^{c}$ \\
\hline Hospital mortality & $1(0.3)$ & $1(0.6)$ & $0(0.0)$ & 1.000 & $0(0.0)$ & $1(0.4)$ & 1.000 & $0(0.0)$ & $1(0.4)$ & 1.000 \\
\hline
\end{tabular}

Values are presented as median (interquartile range) or number (percentage). $p$ values from a Proportions $X 2$ or Fisher exact tests for proportions and MannWhitney $U$ Test for continuous variables ARDS Acute respiratory distress syndrome, ICU Intensive care unit, Intra-OP Intraoperative, LOS Length of stay, MV Mechanical ventilation, NIV Non-invasive ventilation, OLV One lung ventilation, PPC Postoperative pulmonary complication, RM Recruitment maneuvers, TLV Total lung ventilation

a excluding need of oxygen

bunplanned admission

${ }^{c} p$ value from the Cox proportional hazard model

protective ventilation strategy $[3,7,25]$. In average, $10.7 \%$ of patients at increased risk, for example obese patients, developed PPCs [29]. In patients undergoing thoracic surgery, an incidence of PPCs between 10.7 and $50 \%$ has been reported [26, 30-32]. This relatively wide range is possibly explained by differences in definition of pulmonary complications among trials. The rate of severe PPCs was $17.5 \%$ in our thoracic surgery population, which is comparable to the rate of $18.1 \%$ reported by Blank and colleagues [26].

The observation that patients who developed PPCs had more comorbidities and longer LOS is in line with previous studies addressing intraoperative $\operatorname{TLV}[3,33]$. The difference in LOS in the subgroups is likely explained by the type of procedure per se, where open approaches require a prolonged treatment due to more complex procedures, independent from the type of mechanical ventilation.

Although the incidence of PPCs was relatively high, neither open thoracic surgery procedures, nor OLV itself were associated with them, especially when taking the infrequent use of protective mechanical ventilation in this population into account. The precise role of PEEP for protective intraoperative mechanical ventilation has been challenged in recent trials $[7,34]$. In fact, it has been suggested that a strategy aimed at permissive atelectasis might be as protective as a strategy to open lungs during surgery $[14,35]$. Our finding that higher $V_{T}$ was not associated with PPCs is intriguingly, but in agreement with data from an observational study reporting that the use of $\mathrm{V}_{\mathrm{T}}$ as high as $8 \mathrm{~mL} / \mathrm{kg}$ as even associated with better pulmonary outcome [26]. Together, these findings suggest that protective OLV settings are more complex than previously thought. Cutoff values, although valuable, must not only consider the interaction among variables, but also a possible role of airway pressures.

\section{Limitations}

This study has several limitations. First, a one-week inclusion period was relatively short in order to include a 


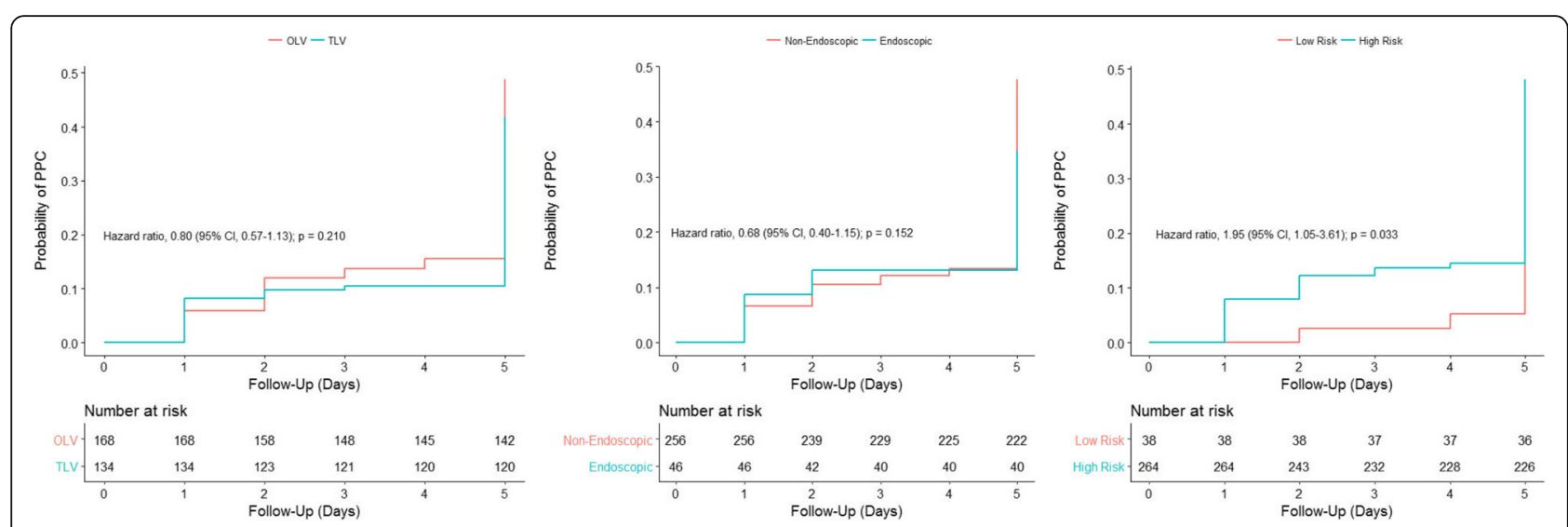

Fig. 1 Probability of PPC according to the subgroups assessed. PPC: postoperative pulmonary complications; OLV: one-lung ventilation; TLV: two-lung ventilationNon-adjusted hazard ratios.

high number of patients per center. However, this fact was counterbalanced by the multicenter design. Second, a short inclusion period might have resulted in selection bias, since fluctuation of the severity of cases cannot be ruled out. Nevertheless, the benefits of avoiding changes in therapy during the observation period as a potential confounder should not be underestimated. Third, the definition of protective mechanical ventilation was based on recommendations that are still under debate. Fourth, most study sites included less than 10 patients. This number, however, does not imply lack of experience with the procedure, since thoracic anesthesia per se already requires a substantial degree of expertise. Fifth, the duration of OLV was not investigated and, therefore, the exact contribution of OLV to PPCs cannot be separated from the period under TLV in this sub-population. Sixth, the design of this study precludes the possibility of determining cause-effect relationships, and results must be seen from a hypothesis-generating perspective. Seventh, the fact that data was collected prospectively might have interfered with clinical practice itself, and biased towards the use of protective ventilation. Still, nonprotective ventilation was used in a vast majority of patients. Eighth, the total number of patients enrolled allowed analyses of three subgroups only. Potential confounders could be the type of anesthesia (total intravenous anesthesia vs. volatile anesthetics), the type of postoperative analgesia (epidural anesthesia vs. opioids) or the ASA status, which should be subject of future trials.

\section{Conclusions}

The present study provides relevant insight into the practice of mechanical ventilation during thoracic surgery. The data might prove useful for the development of scores for risk prediction in this particular population, allocation of human and financial resources, including need for postoperative monitoring in dedicated units, and also estimation of sample size in interventional trials [18]. Mechanical ventilation practice did not follow
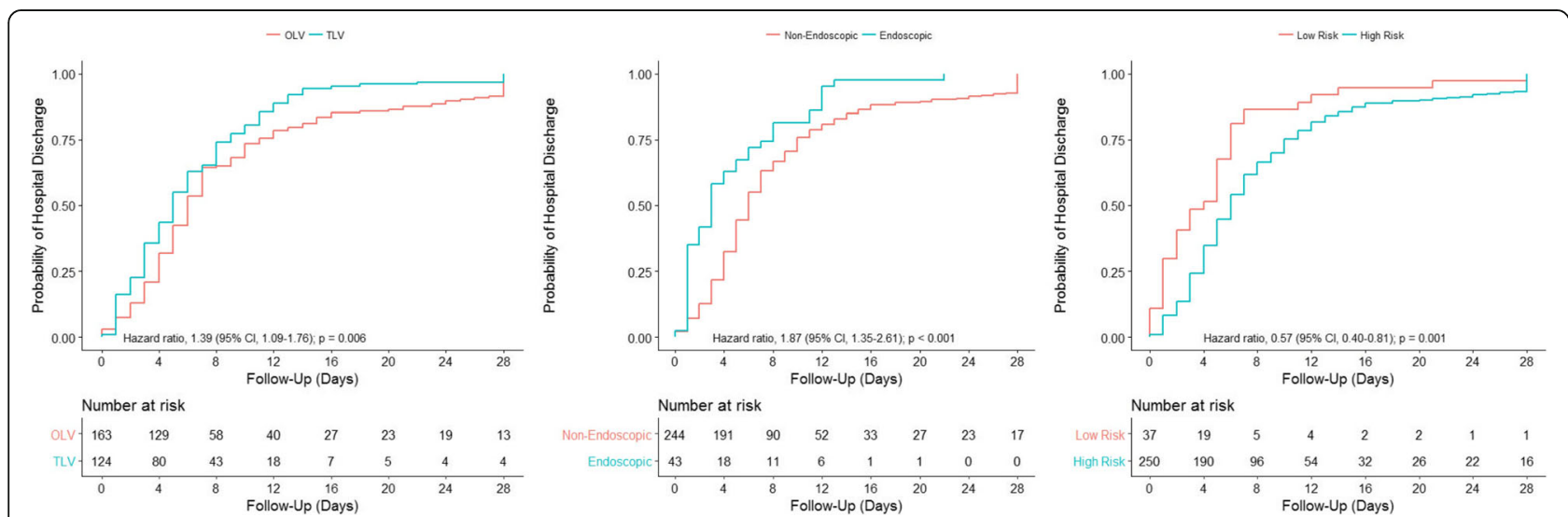

Fig. 2 Probability of hospital discharge according to the subgroups assessed. OLV: one-lung ventilation; TLV: two-lung ventilation. Non-adjusted hazard ratios 
current recommendations for lung protection in the vast majority of patients undergoing thoracic surgery. Although PPCs were common in this population, and associated with increased LOS, their incidence was not higher following open vs. endoscopic or OLV vs. TLV, and not associated with mechanical ventilation settings. It must be emphasized that the lack of association between mechanical ventilation settings and PPCs does not support use of non-protective $\mathrm{V}_{\mathrm{T}}$ and PEEP in this population.

\section{Supplementary information}

Supplementary information accompanies this paper at https://doi.org/10. 1186/s12871-020-01098-4.

Additional file 1: This PDF file contains a list of the LAS VEGAS Thorax study collaborators; Table S1. Participating centers; Table S2. ARISCAT Risk Score; Figure S1. Flowchart; Figure S2. Tidal volume, driving pressure, $\mathrm{PEEP}$ and $\mathrm{FiO}_{2}$ over time according to the use of one-lung ventilation or two-lung ventilation; Figure S3. Tidal volume, driving pressure, PEEP and $\mathrm{FiO}_{2}$ over time in endoscopic or open procedures; Figure S4. Tidal volume, driving pressure, PEEP and $\mathrm{FiO}_{2}$ over time according to the risk for PPC; Figure S5. Combinations of tidal volume and PEEP in the first three hours and last hour of surgery according to the use of onelung ventilation or two-lung ventilation; Figure S6. Combinations of tidal volume and PEEP in the first three hours and last hour of surgery in endoscopic or non-endoscopic procedures; Figure S7. Combinations of tidal volume and PEEP in the first three hours and last hour of surgery according to the risk for PPC and Figure S8. Probability of hospital discharge according to development of PPC.

\section{Abbreviations}

ARISCAT Score: Assess Respiratory Risk in Surgical Patients in Catalonia Score; ESA: European Society of Anaesthesiology; $\mathrm{F}_{1} \mathrm{O}_{2}$ : Fraction of inspired oxygen; LAS VEGAS: Local assessment of ventilatory management during general anesthesia for surgery and effects on postoperative pulmonary complications; LOS: Length of stay; NMBAs: Neuromuscular blocking agents; OLV: Open lung ventilation; PBW: Predicted body weight; PEEP: Positive endexpiratory pressure; Pplat: Plateau pressure; PPCs: Postoperative pulmonary complications; PROVEnet: Protective Ventilation Network; TLV: Total lung ventilation; TOF: Train-of-four stimulation; $\mathrm{SpO}_{2}$ : Peripheral oxygen saturation; STROBE: Strengthening the reporting of observational studies in epidemiology; $V_{\mathrm{T}}$ : Tidal volume

\section{Acknowledgements}

The authors thank the European Society of Anaesthesiology (ESA) for cosponsoring and endorsement as well as assistance in developing and hosting of the electronic case record forms, database and recruiting study sites.

The LAS VEGAS Study Collaborators

Collaborators are listed in the supplemental material (Additional file 1, pp. 2-5).

\section{Authors' contributions}

CU collected data, performed statistical analysis and contributed to the manuscript, ASN: performed statistical analysis and helped preparing the manuscript, MVDW: contributed to the trial design, analysis plan and assisted preparing the manuscript, TK, JW, BS, HS, MH, MVM, DS and NC collected data and contributed to the manuscript, PP: contributed to the trial design, analysis plan and assisted preparing the manuscript. MS: contributed to the trial design, analysis plan and assisted preparing the manuscript. MGA: contributed to the trial design, analysis plan and assisted preparing the manuscript. All authors have read and approved the manuscript.

\section{Funding}

The present trial was financially supported by a grant and endorsed by the European Society of Anaesthesiology (ESA). The ESA had no influence on the data analysis or the content of the manuscript.

\section{Availability of data and materials}

The datasets used and/or analyzed during the current study are available from the corresponding author on reasonable request.

\section{Ethics approval and consent to participate}

The trial protocol was first approved by the institutional review board of the Academic Medical Center, Amsterdam, The Netherlands

(W12_190\#12.17.0227). Written informed consent was obtained from all participants prior to trial enrollment.

\section{Consent for publication}

Not applicable.

\section{Competing interests}

All authors declare that they have no competing interests.

\section{Author details}

${ }^{1}$ Department of Anaesthesiology and Intensive Care Medicine, Pulmonary Engineering Group, University Hospital Carl Gustav Carus at the Technische Universität Dresden, Fetscherstr. 74, 01307 Dresden, Germany. ${ }^{2}$ Department of Critical Care Medicine \& Institute of Education and Research, Hospital Israelita Albert Einstein, São Paulo, Brazil. ${ }^{3}$ Department of Intensive Care Medicine and Laboratory of Experimental Intensive Care and Anesthesiology, Academic Medical Center, University of Amsterdam, Amsterdam, The Netherlands. ${ }^{4}$ Academic Unit of Anaesthesia, Pain and Critical Care, Golden Jubilee National Hospital / West of Scotland Heart and Lung Centre University of Glasgow, Glasgow, UK. ${ }^{5}$ Division Cardiac, Thoracic, Vascular Anesthesia and Intensive Care, Medical University Vienna, Vienna, Austria. ${ }^{6}$ Department of Anesthesia, Critical Care and Pain Medicine, Massachusetts General Hospital and Harvard Medical School, Boston, MA, USA. ${ }^{7}$ Division of Anaesthesiology and Intensive Care, IEO Istituto Europeo di Oncologia, Milan, Italy. ${ }^{8}$ Department of Anaesthesiology and Reanimation, Akdeniz University Hospital, Antalya, Turkey. ${ }^{9}$ Department of Surgical Sciences and Integrated Diagnostics, IRCCS San Martino IST, University of Genoa, Genoa, Italy.

Received: 14 April 2020 Accepted: 15 July 2020

Published online: 22 July 2020

\section{References}

1. Weiser TG, Regenbogen SE, Thompson KD, Haynes AB, Lipsitz SR, Berry WR, Gawande AA. An estimation of the global volume of surgery: a modelling strategy based on available data. Lancet. 2008;372(9633):139-44.

2. Bainbridge D, Martin J, Arango M, Cheng D, Evidence-based Peri-operative clinical outcomes research G. Perioperative and anaesthetic-related mortality in developed and developing countries: a systematic review and metaanalysis. Lancet. 2012;380(9847):1075-81.

3. Investigators LV. Epidemiology, practice of ventilation and outcome for patients at increased risk of postoperative pulmonary complications: LAS VEGAS - an observational study in 29 countries. Eur J Anaesthesiol. 2017; 34(8):492-507.

4. Senturk M. New concepts of the management of one-lung ventilation. Curr Opin Anaesthesiol. 2006;19(1):1-4.

5. Severgnini P, Selmo G, Lanza C, Chiesa A, Frigerio A, Bacuzzi A, Dionigi G, Novario R, Gregoretti C, de Abreu MG, et al. Protective mechanical ventilation during general anesthesia for open abdominal surgery improves postoperative pulmonary function. Anesthesiology. 2013;118(6):1307-21.

6. Hemmes SN, Serpa Neto A, Schultz MJ. Intraoperative ventilatory strategies to prevent postoperative pulmonary complications: a meta-analysis. Curr Opin Anaesthesiol. 2013;26(2):126-33.

7. PROVE Network Investigators for the Clinical Trial Network of the European Society of Anaesthesiology; Sabrine N T Hemmes, Marcelo Gama de Abreu, Pelosi P, Schultz MJ. High versus low positive end-expiratory pressure during general anaesthesia for open abdominal surgery (PROVHILO trial): a multicentre randomised controlled trial. Lancet. 2014;384(9942):495-503.

8. Young CC, Harris EM, Vacchiano C, Bodnar S, Bukowy B, Elliott RRD, Migliarese J, Ragains C, Trethewey B, Woodward A, et al. Lung-protective 
ventilation for the surgical patient: international expert panel-based consensus recommendations. Br J Anaesth. 2019;123(6):898-913.

9. Hemmes SN, de Abreu MG, Pelosi P, Schultz MJ. ESA clinical trials network 2012: LAS VEGAS--local assessment of Ventilatory management during general Anaesthesia for surgery and its effects on postoperative pulmonary complications: a prospective, observational, international, multicentre cohort study. Eur J Anaesthesiol. 2013;30(5):205-7.

10. Arozullah AM, Daley J, Henderson WG, Khuri SF. Multifactorial risk index for predicting postoperative respiratory failure in men after major noncardiac surgery. The National Veterans Administration Surgical Quality Improvement Program. Ann Surg. 2000;232(2):242-53.

11. Arozullah AM, Khuri SF, Henderson WG, Daley J, Participants in the National Veterans Affairs Surgical Quality Improvement P. Development and validation of a multifactorial risk index for predicting postoperative pneumonia after major noncardiac surgery. Ann Intern Med. 2001;135(10):847-57.

12. Canet J, Gallart L, Gomar C, Paluzie G, Valles J, Castillo J, Sabate S, Mazo V, Briones Z, Sanchis J, et al. Prediction of postoperative pulmonary complications in a population-based surgical cohort. Anesthesiology. 2010;113(6):1338-50.

13. Smetana GW. Preoperative pulmonary evaluation: identifying and reducing risks for pulmonary complications. Cleve Clin J Med. 2006; 73(Suppl 1):S36-41.

14. Guldner A, Kiss T, Serpa Neto A, Hemmes SN, Canet J, Spieth PM, Rocco PR, Schultz MJ, Pelosi P, Gama de Abreu M. Intraoperative protective mechanical ventilation for prevention of postoperative pulmonary complications: a comprehensive review of the role of tidal volume, positive end-expiratory pressure, and lung recruitment maneuvers. Anesthesiology. 2015;123(3):692-713.

15. Serpa Neto A, Hemmes SN, Barbas CS, Beiderlinden M, Biehl M, Binnekade JM, Canet J, Fernandez-Bustamante A, Futier E, Gajic O, et al. Protective versus conventional ventilation for surgery: a systematic review and individual patient data Meta-analysis. Anesthesiology. 2015;123(1):66-78.

16. Futier $E$, Marret $E$, Jaber $S$. Perioperative positive pressure ventilation: an integrated approach to improve pulmonary care. Anesthesiology. 2014; 121(2):400-8.

17. Slutsky AS, Ranieri VM. Ventilator-induced lung injury. N Engl J Med. 2013; 369(22):2126-36.

18. Kiss T, Wittenstein J, Becker C, Birr K, Cinnella G, Cohen E, El Tahan MR, Falcao LF, Gregoretti C, Granell M, et al. Protective ventilation with high versus low positive end-expiratory pressure during one-lung ventilation for thoracic surgery (PROTHOR): study protocol for a randomized controlled trial. Trials. 2019;20(1):213.

19. Marret E, Cinotti R, Berard L, Piriou V, Jobard J, Barrucand B, Radu D, Jaber S, Bonnet $F$, the PPVsg. Protective ventilation during anaesthesia reduces major postoperative complications after lung cancer surgery: a double-blind randomised controlled trial. Eur J Anaesthesiol. 2018;35(10):727-35.

20. Lohser J, Slinger P. Lung injury after one-lung ventilation: a review of the pathophysiologic mechanisms affecting the ventilated and the collapsed lung. Anesth Analg. 2015;121(2):302-18.

21. von Elm E, Altman DG, Egger M, Pocock SJ, Gotzsche PC, Vandenbroucke $J P$, Initiative $S$. The strengthening the reporting of observational studies in epidemiology (STROBE) statement: guidelines for reporting observational studies. Int J Surg. 2014;12(12):1495-9.

22. Bendixen $\mathrm{HH}$, Hedley-Whyte J, Laver MB. Impaired oxygenation in surgical patients during general anesthesia with controlled ventilation. A concept of atelectasis. N Engl J Med. 1963;269:991-6.

23. Benumof J. Conventional and differential lung management of one-lung ventilation. In: Anesthesia for thoracic surgery. Philadelphia: Saunders, W.B; 1995. p. 799.

24. Slinger P. Perioperative lung injury. Best Pract Res Clin Anaesthesiol. 2008; 22(1):177-91.

25. Futier $\mathrm{E}$, Constantin JM, Paugam-Burtz C, Pascal J, Eurin M, Neuschwander $A$, Marret E, Beaussier M, Gutton C, Lefrant JY, et al. A trial of intraoperative low-tidal-volume ventilation in abdominal surgery. N Engl J Med. 2013; 369(5):428-37.

26. Blank RS, Colquhoun DA, Durieux ME, Kozower BD, McMurry TL, Bender SP, Naik BI. Management of one-lung Ventilation: impact of tidal volume on complications after thoracic surgery. Anesthesiology. 2016;124(6):1286-95.

27. Colquhoun DA, Naik BI, Durieux ME, Shanks AM, Kheterpal S, Bender SP Blank RS, Investigators M. Management of 1-lung ventilation-variation and trends in clinical practice: a report from the multicenter perioperative outcomes group. Anesth Analg. 2018;126(2):495-502.
28. Blank RS, Lesh RE. Low tidal volume ventilation in the surgical patient: not particularly low and perhaps not particularly protective. Anesth Analg. 2019; 128(4):831-3.

29. Ball L, Hemmes SNT, Serpa Neto A, Bluth T, Canet J, Hiesmayr M, Hollmann MW, Mills GH, Vidal Melo MF, Putensen C, et al. Intraoperative ventilation settings and their associations with postoperative pulmonary complications in obese patients. Br J Anaesth. 2018;121(4):899-908.

30. Baudouin SV. Lung injury after thoracotomy. Br J Anaesth. 2003;91 (1):132-42.

31. Cao C, Louie BE, Melfi F, Veronesi G, Razzak R, Romano G, Novellis P, Ranganath NK, Park BJ. Impact of pulmonary function on pulmonary complications after robotic-assisted thoracoscopic lobectomy. Eur J Cardiothorac Surg. 2020; 57(2):338-342.

32. Im Y, Park HY, Shin S, Shin SH, Lee H, Ahn JH, Sohn I, Cho JH, Kim HK, Zo J, et al. Prevalence of and risk factors for pulmonary complications after curative resection in otherwise healthy elderly patients with early stage lung cancer. Respir Res. 2019;20(1):136.

33. Serpa Neto A, Hemmes SN, Barbas CS, Beiderlinden M, FernandezBustamante A, Futier E, Hollmann MW, Jaber S, Kozian A, Licker M, et al. Incidence of mortality and morbidity related to postoperative lung injury in patients who have undergone abdominal or thoracic surgery: a systematic review and meta-analysis. Lancet Respir Med. 2014;2(12):1007-15.

34. Writing Committee for the PCGotPVNftCTNotESoA, Bluth T, Serpa Neto A, Schultz MJ, Pelosi P, Gama de Abreu M. Effect of Intraoperative High Positive End-Expiratory Pressure (PEEP) With Recruitment Maneuvers vs Low PEEP on Postoperative Pulmonary Complications in Obese Patients: A Randomized Clinical Trial. JAMA. 2019:321(23):2292-305.

35. Pelosi P, Rocco PRM, Gama de Abreu M. Close down the lungs and keep them resting to minimize ventilator-induced lung injury. Crit Care. 2018; $22(1): 72$.

\section{Publisher's Note}

Springer Nature remains neutral with regard to jurisdictional claims in published maps and institutional affiliations.

\section{Ready to submit your research? Choose BMC and benefit from:}

- fast, convenient online submission

- thorough peer review by experienced researchers in your field

- rapid publication on acceptance

- support for research data, including large and complex data types

- gold Open Access which fosters wider collaboration and increased citations

- maximum visibility for your research: over $100 \mathrm{M}$ website views per year

At BMC, research is always in progress.

Learn more biomedcentral.com/submissions 